\title{
Activation of AKR1C1/ERß induces apoptosis by downregulation of C-FLIP in prostate cancer cells: A prospective therapeutic opportunity
}

\author{
Huiyoung Yun ${ }^{1,2, *}$, Jianping Xie ${ }^{1,7, *}$, Aria F. Olumi ${ }^{3}$, Rita Ghosh ${ }^{1,2,4,5}$, Addanki P. \\ Kumar ${ }^{1,2,4,5,6}$ \\ ${ }^{1}$ Department of Urology, The University of Texas Health Science Center, San Antonio, TX, USA \\ ${ }^{2}$ Department of Pharmacology, The University of Texas Health Science Center, San Antonio, TX, USA \\ ${ }^{3}$ Department of Urology, Massachusetts General Hospital Harvard Medical School, Boston, MA, USA \\ ${ }^{4}$ Department of Molecular Medicine, The University of Texas Health Science Center, San Antonio, TX, USA \\ ${ }^{5}$ Cancer Therapy and Research Center, The University of Texas Health Science Center, San Antonio, TX, USA \\ ${ }^{6}$ South Texas Veterans Health Care System, San Antonio, TX, USA \\ ${ }^{7}$ Department of Urology, Shanxi Dayi Hospital, Shanxi Academy of Medical Science, Taiyuan, P.R., China \\ *These authors have contributed equally to this work
}

Correspondence to:

Addanki P. Kumar, e-mail: kumara3@uthscsa.edu

Keywords: androgen receptor, estrogen receptor beta, C-FLIP, 2-methoxyestradiol, transcription factor

Received: January 28, 2015

Accepted: February 19, 2015

Published: March 24, 2015

\section{ABSTRACT}

We provide first-time evidence for ERß-mediated transcriptional upregulation of c-FLIP as an underlying mechanism in the development of castrate-resistant cancer. While androgens inhibit apoptosis partly through transcriptional upregulation of the anti-apoptotic protein, c-FLIP in androgen-responsive cells, they downregulate c-FLIP in androgen-independent cells. We found that although Sp1 and p65 transactivate c-FLIP, the combination of Sp1 and p65 has differential effects in a cellular context-dependent manner. We show that activation of the androgen metabolism enzyme, aldo-keto reductase, AKR1C1, relieves androgen independence through activation of $3 \beta$-Adiol-mediated upregulation of ERß. ER $\beta$ competes with Sp1 and Sp3 to transcriptionally downregulate c-FLIP in the absence of consensus estrogenresponse element in androgen-independent cells. Forced expression of AR in androgenindependent cells show that ER $\beta$-mediated growth inhibition occurs under conditions of androgen independence. Reactivation of ER $\beta$ with the estrogenic metabolite, 2-methoxyestradiol, decreased enrichment ratio of $\mathrm{Sp1/Sp3}$ at the c-FLIP promoter with concomitant effects on cell growth and death. Expression of Sp1 and c-FLIP are elevated while AKR1C1, ERß and Sp3 are significantly low in human prostate tumor samples. ER $\beta$ is epigenetically silenced in prostate cancer patients, therefore our results suggest that combination of ER $\beta$ agonists with ADT would benefit men stratified on the basis of high estrogen levels.

\section{INTRODUCTION}

The binding of androgens to the androgen receptor (AR) plays an important role not only in the growth and development of normal prostate, but also in prostatic diseases including prostate cancer (PCA). Accordingly, androgen deprivation therapy (ADT) is the mainstay therapeutic approach for locally advanced PCA [1]. Although initially effective, the outcome is transient, invariably resulting in progression to aggressive metastatic castrate-resistant form (CRPC) with no effective curative options [2]. ADT functions by causing apoptotic cell death of cancer cells. However, advanced prostate cancer cells develop resistance to ADT-induced apoptosis leading to development of aggressive castrate-resistant status [3]. Additionally, though PCA is an androgen-dependent disease, levels of androgens 
decrease while estrogens increase with age [4]. Accordingly, it was suggested that rather than androgens per se, the ratio of androgen to estrogens may be a potential reason for development of CRPCA [5]. This is corroborated by emerging evidence implicating a role of estrogen receptors (ERs) primarily $\alpha$ and $\beta$ (ER $\alpha$ and $\beta$ ) in prostate cancer cells and human prostate tumors [6, 7]. Furthermore, ectopic expression of ER $\beta$ inhibits growth, migration, invasion and epithelial mesenchymal transition of prostate cancer cells and ER $\beta$ knockout mice develop hyperplasia and PIN lesions [7, 8]. However, the underlying mechanism of ER $\beta$-mediated prostate pathogenesis including CRPCA is undefined. Studies to understand the molecular events associated with CRPCA identified an important role for the anti-apoptotic FLICE-inhibitory protein (c-FLIP) [11]. c-FLIP is aberrantly expressed in high-grade and castrateresistant human prostate tumors. Furthermore, nude mice implanted with c-FLIP overexpressing LNCaP cells develop androgen independent prostate tumors suggesting androgen regulation of c-FLIP. Evidence from epidemiological and laboratory studies indicate lower PCA incidence in men consuming soy products [12]. Gut microbial digestion of these products generates estrogenic metabolites with antitumorigenic activity [12]. Along these lines, studies from number of laboratories including our own demonstrated antitumorigenic activity for a non-toxic endogenous estrogenic metabolite 2-methoxyestradiol (2-ME $)$ in multiple tumor types in vitro and in vivo [13-17]. In addition, downregulation of c-FLIP by $2-\mathrm{ME}_{2}$ has been reported to inhibit tumor growth in vitro and in vivo [13-17]. Despite the circumstantial evidence, the underlying mechanism through which androgens and loss of ER $\beta$ influence c-FLIP deregulation during prostate carcinogenesis and whether 2-ME - -mediated inhibition of prostate tumor development involves ER $\beta / c$-FLIP remains to be defined.

Here we investigated the functional interaction between androgen metabolism-mediated activation of ER $\beta$ as a possible underlying mechanism involved in deregulation of c-FLIP. We provide evidence that c-FLIP is negatively regulated by ER $\beta$ possibly through modulation of $\mathrm{Sp} 1 / \mathrm{Sp} 3$ binding to its promoter. We also provide evidence that inhibition of Sp1 activation coupled with $\mathrm{ER} \beta$ activation with 2-ME ${ }_{2}$ suppresses tumor cell growth and induces apoptosis. These findings identify ER $\beta$ as a negative modulator of c-FLIP and suggest strategies to target ER $\beta$ activation either directly or by enhancing androgen metabolism enzyme AKR1C1 along with AR inhibition as a novel approach for effective management of CRPCA.

\section{RESULTS}

\section{Differential regulation of c-FLIP by Sp1 and $\mathrm{NF} \kappa \mathrm{B}$ in prostate cancer cells}

Although published studies have demonstrated that $2-\mathrm{ME}_{2}$ inhibits prostate cancer cell growth by suppressing transcriptional activation of c-FLIP, the molecular mechanism through which 2-ME ${ }_{2}$ suppresses c-FLIP activation is not defined [13]. Transient expression assays using exonuclease deletion constructs spanning the 5 'flanking region of c-FLIP promoter element identified $-121 /+242$ sequence with maximal constitutive reporter activity in both androgen-responsive $\mathrm{LNCaP}$ and androgen-independent prostate cancer cells PC-3 and DU145 cells (Fig. 1A-1C). Interestingly, promoter activity increased significantly in response to androgens (5 $\alpha$-DHT stimulation) in LNCaP cells (Fig. 1C and data not shown). Constitutive c-FLIP promoter activity in PC-3 and DU145 cells or $5 \alpha$-DHT-stimulated activity in LNCaP cells decreased following treatment with $2-\mathrm{ME}_{2}$. Inclusion of sequence elements upstream of -121 not only decreased the basal promoter activity but also the $2-\mathrm{ME}_{2}$ response. These data suggest that $2-\mathrm{ME}_{2}$ response elements are located within sequence elements $-121 /+242$ and that this sequence element was sufficient to maintain the c-FLIP core promoter activity.

Analysis of $-121 /+242$ sequence identified putative binding sites for multiple transcription factors including AR, Sp1 and NFkB (Supplementary Fig. S1A). Therefore, we tested the impact of ectopic expression of Sp1, Sp3 and p65 (NFkB) on c-FLIP promoter activity using co-transfections. Ectopic expression of $\mathrm{Sp} 1$ or p65 transactivated c-FLIP in all three prostate cancer cell lines (Fig. 1D-1F). The observed p65-mediated transactivation was repressed in cells co-transfected with phosphorylation defective I $\mathrm{I} B \alpha$ indicating the specificity of NFKB-mediated effects. Interestingly, we observed differential effects of co-transfection with Sp1 on p65 transactivation of c-FLIP promoter. Sp1 repressed p65 transactivation of c-FLIP in DU145 and LNCaP cells (Fig. 1E-1F) with no significant effect in PC-3 cells (Fig. 1D). Furthermore, ectopic expression of Sp3 or treatment with $2-\mathrm{ME}_{2}$ inhibited both $\mathrm{Sp} 1$ and $\mathrm{p} 65-$ mediated transactivation (Fig. 1D-1F). These data suggest (i) Sp1 as master regulator of c-FLIP; and (ii) either Sp1 or p65 can individually transactivate c-FLIP, and that the combination of Sp1 and p65 can have differential effects depending on the cell type.

\section{Identification and characterization of DNA- protein complexes binding to c-FLIP promoter}

Chromatin immunoprecipitation assay (ChIP) was used to examine whether Sp1 regulates endogenous c-FLIP in the context of chromatin using overlapping binding sites for Sp1 and p65 (Supplementary Fig. S1B). Chromatin immunoprecipitated extracts from untreated DU145 but not PC-3 cells with anti-Sp1 antibody amplified c-FLIP sequence (Fig. 2A and 2B). It is noteworthy to mention here that $\mathrm{Sp} 1$ was recruited to the c-FLIP sequences upstream of -833 (data not shown). In contrast, in LNCaP cells significant enrichment of Sp1 was observed only 
A

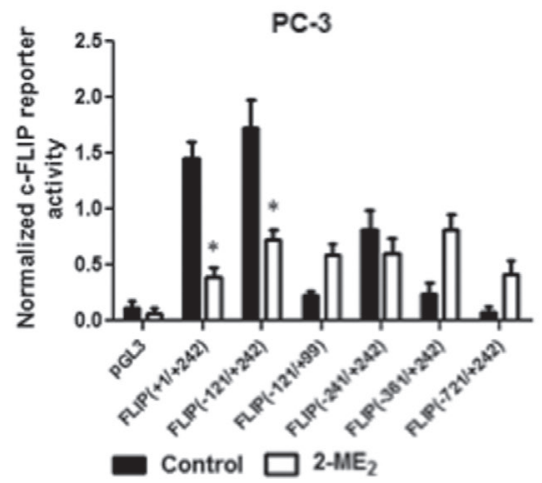

B

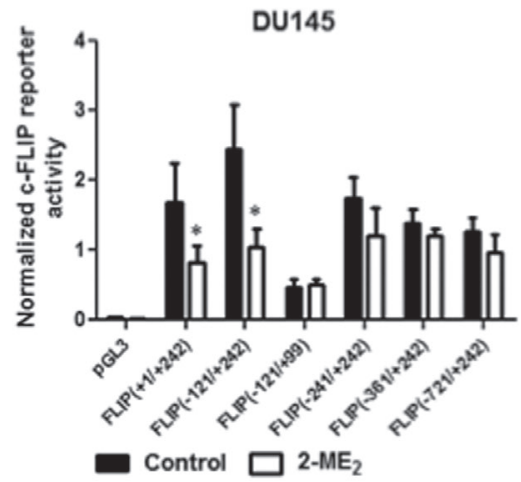

C

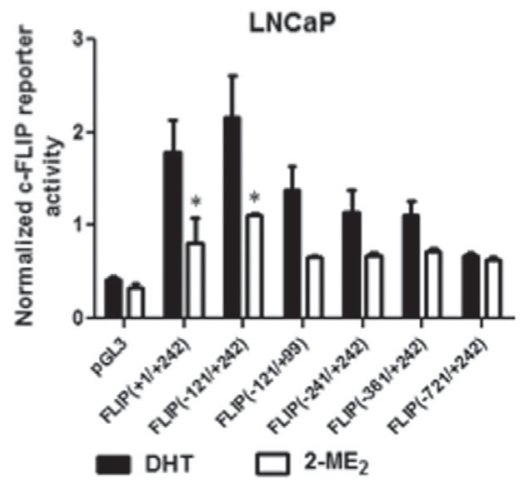

D

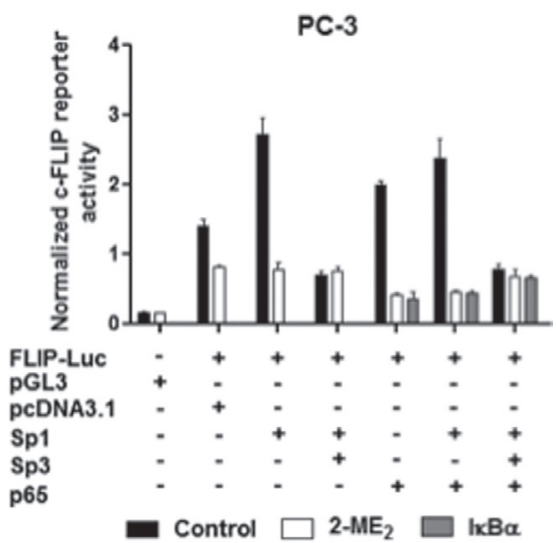

$\mathbf{E}$



$\mathbf{F}$



Figure 1: Identification of core c-FLIP promoter elements sufficient for constitutive and 2-ME ${ }_{2}$ response, and regulation of c-FLIP with multiple transcription factors including Sp1, Sp3 and NFкB. A-C. Androgen independent PC-3, DU145, and androgen-responsive LNCaP cells were transfected with indicated deletion constructs of c-FLIP reporter plasmid $(0.5 \mu \mathrm{g})$. Posttransfection, cells were treated with 2- $\mathrm{ME}_{2}(3 \mu \mathrm{M}$ for $\mathrm{LNCaP}$ and $\mathrm{PC}-3$, and $5 \mu \mathrm{M}$ for DU145) for $24 \mathrm{~h}$. Luciferase activity was measured. Cells transfected with pGL3 empty vector was used as negative control. Data presented is average \pm S.E.M of three independent experiments conducted in triplicate. ${ }^{*} p<0.05$. D-F. PC-3, DU145 and LNCaP cells were co-transfected with pGL3-FLIP $(-121 /+242)$-Luc plasmid along with empty vector (pCMV3.1) or expression plasmids for (pCMV-Sp1, pCMV-Sp3, pCMV-p65 or IkB $\alpha$ mutant, a super repressor of NFkB $\left(0.5 \mu \mathrm{g} /\right.$ well of each). Post-transfection, cells were treated with $2-\mathrm{ME}_{2}$ for $24 \mathrm{~h}$ and luciferase activity was measured. Cells transfected with empty vector was used as negative control. Data presented is average \pm S.E.M of three independent experiments conducted in triplicate.

under androgen-stimulated conditions (Fig. 2C). Treatment with 2-ME reduced $\mathrm{Sp} 1$ but enhanced $\mathrm{Sp} 3$ enrichment in DU145 cells with no significant effect in LNCaP cells. No significant change in binding to $\beta$-actin (negative control) was observed under these conditions. It should be noted that in transient expression assays Sp1 transactivates c-FLIP promoter in PC-3 cells. These surprising findings lead us to examine p65 binding (given its overlap with 
A

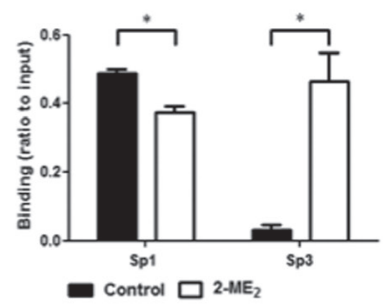

D

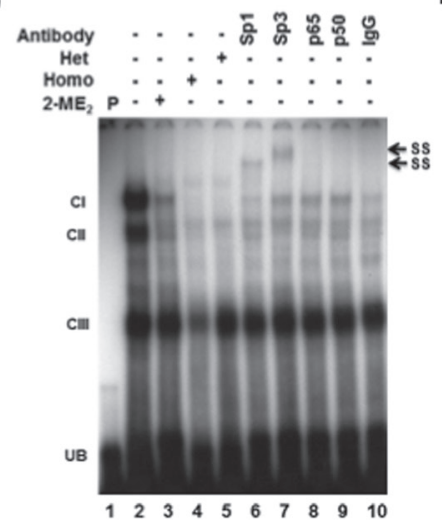

B

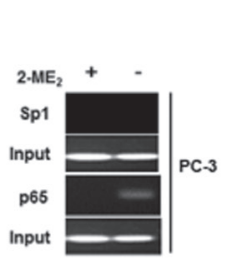

E

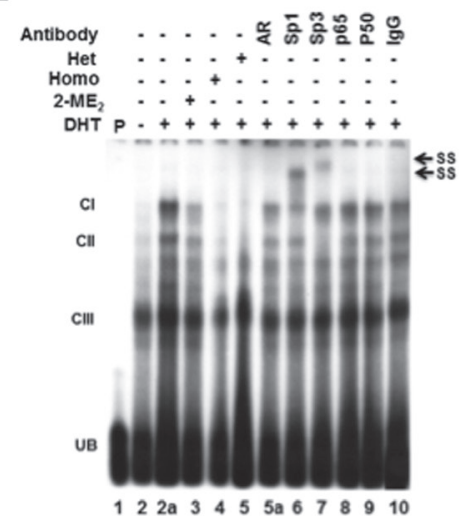

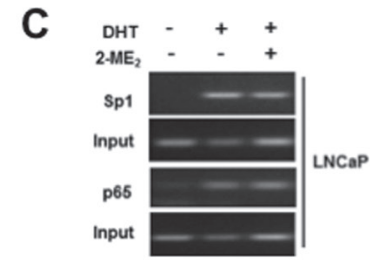

$\mathbf{F}$

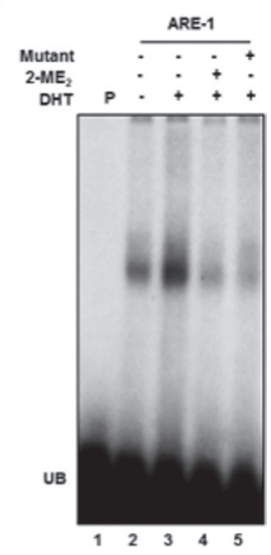

Figure 2: Sp1, Sp3 and NFkB bind to the endogenous c-FLIP promoter. A. DU145 cells were untreated or treated with 2-ME $(5 \mu \mathrm{M})$ for $24 \mathrm{~h}$, and chromatin immunoprecipitation quantitative real-time PCR (ChIP-qPCR) was performed using anti-Sp1 or anti-Sp3 antibody. The amplification value from immunoprecipitated DNA was normalized to $10 \%$ input. Error bars indicate \pm S.E.M. $(n=3)$. ${ }^{*} p<0.05$. B. PC-3 cells were untreated or treated with $2-\mathrm{ME}_{2}(5 \mu \mathrm{M})$ for $24 \mathrm{~h}$. C. LNCaP cells were untreated or treated with $2-\mathrm{ME}_{2}$ $(3 \mu \mathrm{M})$ for $6 \mathrm{~h}$ in the presence or absence of DHT $(1 \mathrm{nM})$. Gel-based ChIP-PCR was performed using anti-Sp1 or anti-p65 antibody. D. Binding of AR, Sp1, Sp3 and 655 to the c-FLIP promoter sequence elements containing Sp1, NFKB, or AR binding sites to nuclear extracts prepared from PC-3 cells using electrophoretic mobility shift assay (EMSA). PC-3 cells untreated or treated with 2-ME ${ }_{2}(3 \mu \mathrm{M})$ for $24 \mathrm{~h}$. Radiolabeled c-FLIP probe was preincubated with 100-fold molar excess of unlabeled c-FLIP sequence (homologous) or Sp1 oligonucleotide with mutation (heterologous) for 5 min prior to incubation with nuclear extracts. Nuclear extracts pre-incubated with indicated antibodies for 30 minutes on ice were used in super-shift experiments. E. Nuclear extracts prepared from LNCaP cells untreated or pretreated with 2-ME ${ }_{2}(3 \mu \mathrm{M})$ for $6 \mathrm{~h}$ prior to stimulation with DHT $(1 \mathrm{nM})$ for $1 \mathrm{~h}$ were used in EMSA. EMSA was carried out essentially as described above. F. Binding of nuclear extracts from untreated or $5 \alpha$-DHT stimulated LNCaP cells to c-FLIP ARE-1 (+57/+71) as radiolabeled probe was shown. (CI-III: DNA-protein complexes, UB: unbound free probe, SS: super-shifted bands).

Sp1 site) to endogenous c-FLIP. Interestingly, chromatin immunoprecipitated extracts with anti-p65 specifically bound these sequences that was abolished with $2-\mathrm{ME}_{2}$ in PC-3 cells (Fig. 2B). Taken together, these data suggest multiple transcription factors including $\mathrm{Sp} 1, \mathrm{Sp} 3$ and $\mathrm{NF} \kappa \mathrm{B}$ differentially regulate c-FLIP depending on the cell type and recruitment of both $\mathrm{Sp} 1$ and $\mathrm{p} 65$ to overlapping sites of c-FLIP promoter.

To examine if $\mathrm{Sp} 1$ and $\mathrm{p} 65$ regulate c-FLIP by binding to the same sequence elements, gel super-shift experiments were conducted using c-FLIP promoter sequence (+64/+89 containing $\mathrm{AR}, \mathrm{Sp} 1$ and NFkB overlapping bindings sites; Supplementary Fig. S1C) as radiolabeled probe. Given our data suggesting differential regulation of c-FLIP between LNCaP and DU145 vs. PC-3, we performed gel shift experiments using LNCaP and PC-3 cells. Nuclear extracts from PC-3 or $5 \alpha$-DHT-stimulated LNCaP cells formed three distinct DNA-protein complexes (Complex I, II and III; Fig. 2D and 2E). The observed complexes were either completely
(CI and II) or partially (CIII) abolished in response to $2-\mathrm{ME}_{2}$ treatment (lane 3). Competition experiments using c-FLIP oligo or mutant Sp1 oligonucleotide as homologous or heterologous competitors respectively abolished both CI and II but CIII was partially abolished (lanes 4 and 5). These data suggest the presence of Sp1, Sp-related and factors other than Sp1 in these complexes. Pre-incubation of nuclear extracts with antibodies against Sp1 and Sp3 showed super-shifted complexes (lanes 6 and 7; indicated as SS) or reduced complex formation with p65 and p50 (lanes 8 and 9) in both cell types. In addition, pre-incubation of nuclear extracts from $\mathrm{LNCaP}$ cells with AR antibody partially abolished the observed DNA-protein complex indicating the presence of AR in androgen-responsive cells (lane 5a).

Previous studies have demonstrated the presence of androgen response element (ARE)-1 within this sequence [20]. These data prompted us to perform gel shift experiments using c-FLIP sequence containing wild type ARE-1 (Supplementary Fig. S1D). 5 $\alpha$-DHT-stimulated 
nuclear extracts from LNCaP cells showed enhanced binding to this sequence that was reduced in response to 2- $\mathrm{ME}_{2}$ (lanes 3 and 4; Fig. 2F). Competition experiments using ARE1 with mutation in conserved binding site eliminated the observed DNA-protein complex indicating the presence of factors other than AR, including Sp1 and p65 (lane 5; Fig. 2F). Taken together, these data show the presence of AR, Sp1 and p65 in CI and Sp3 in CII and suggest that AR bound c-FLIP promoter sequence containing $\mathrm{Sp} 1 / \mathrm{NF} \kappa \mathrm{B}$ sequences is upregulated in response to androgens in $\mathrm{LNCaP}$ cells.

\section{Androgen down regulate c-FLIP activation in androgen independent cells}

These results prompted us to examine if Sp1/p65 can mediate androgen regulation of c-FLIP in the absence of AR using AR-negative DU145 cells. Surprisingly, c-FLIP promoter activity was significantly decreased in response to $5 \alpha$-DHT in these cells (lane 3; Fig. 3A). Consistent with data presented in Fig. 1B, 2-ME further reduced the observed basal and $5 \alpha$-DHT-inhibited c-FLIP promoter activity (lanes 2 and 4; Fig. 3A). This unexpected finding prompted us to test if the detected $5 \alpha$-DHT-mediated effects are related to its metabolism. Therefore, we conducted these experiments using non-metabolizable androgen R1881. Interestingly, R1881 had no significant effect on c-FLIP activation, albeit 2-ME ${ }_{2}$ decreased (lanes 5 and 6; Fig. 3A). Next we investigated if the observed $5 \alpha$-DHT-mediated decrease in c-FLIP activation is related to reduced $\mathrm{Sp} 1$ enrichment at the promoter. ChIP analysis showed significant enrichment of Sp3 and non-significant increase in $\mathrm{Sp} 1$ (relative to control IgG antibody) at the endogenous c-FLIP promoter in response to $5 \alpha$-DHT but not R1881 treatment (lanes 2\&7 and 4\&9; Fig. 3B). Remarkably, 2- $\mathrm{ME}_{2}$-treatment showed 10-fold higher enrichment of $\mathrm{Sp} 3$ (relative to control $\mathrm{IgG}$ antibody) to the endogenous c-FLIP promoter following $5 \alpha$-DHTstimulation (lane 8; Fig. 3B). These results suggest that $5 \alpha$-DHT metabolic products could be involved in the observed $5 \alpha$-DHT-induced downregulation of c-FLIP.

Aldo-keto reductase, AKR1C1 predominantly metabolizes $5 \alpha$-DHT into $3 \beta$-Adiol, a physiological ligand for $\operatorname{ER} \beta$ [21]. We examined alterations in the expression of AKR1C1 and ER $\beta$ in DU145 cells and found that $5 \alpha$-DHT and 2-ME significantly up-regulated mRNA expression of AKR1C1 and ER $\beta$ (Fig. 3C). These correlative results led us to hypothesize that metabolic inactivation of $5 \alpha$-DHT by AKR1C1 could produce $3 \beta$-Adiol that in turn reduces c-FLIP transcriptional activation via ER $\beta$ activation. To directly test this, we examined c-FLIP transactivation by ectopically expressing ER $\beta$ or pharmacologically by treating cells with $3 \beta$-Adiol. Ectopic expression of ER $\beta$ (left panel) or treatment with $3 \beta$-Adiol (right panel) decreased c-FLIP promoter activity significantly (Fig. 3D). Similar results were also obtained with PC-3 cells (Fig. 3E). In contrast, 3 $\beta$-Adiol but not $\mathrm{ER} \beta$ decreased c-FLIP promoter activity in LNCaP cells (Fig. 3E bottom panel). Given the differential status of AR between LNCaP and PC3 \& DU145 cells, we reasoned that the presence of AR could be a contributing factor for the observed differential regulation of c-FLIP by ER $\beta$. To address this, we performed similar experiments using PC-3 cells stably overexpressing AR (PC-3 AR). Intriguingly, we did not observe ER $\beta$-mediated down regulation of c-FLIP promoter activity in these cells (Fig. 3F). These data suggest that metabolic inactivation of $5 \alpha$-DHT by AKR1C1 could produce $3 \beta$-Adiol, which in turn reduces c-FLIP transcriptional activation possibly via ER $\beta$ activation. Furthermore, AR inhibits ER $\beta$ mediated inhibition of c-FLIP activation. Given the lack of consensus estrogen response element in the c-FLIP promoter, how ER $\beta$ suppresses c-FLIP is unclear.

\section{ERß competes with $\mathrm{Sp} 1$ and $\mathrm{Sp3}$ for binding to c-FLIP promoter}

Previous studies have shown that estrogen receptors can regulate gene expression non-genomically through interactions with other transcription factors such as Sp1 $[22,23]$. We tested this hypothesis using co-transfection assays in DU145 cells. Consistent with data presented in Figs. 1E and 3D; ectopic expression of Sp1 transactivated while Sp3 trans-repressed Sp1-mediated activation (lanes 2 and 3; Fig. 4A). On the other hand, ectopic ER $\beta$ expression not only suppressed constitutive \& $\mathrm{Sp} 1$-mediated activation but also $\mathrm{Sp} 3$-mediated inhibition c-FLIP activation (lanes 4-7; Fig. 4A). Furthermore, ectopic ER $\beta$ expression further suppressed Sp3-mediated inhibition of Sp1 transactivation (lane 8; Fig. 4A). Although the biological significance of these observations is unclear, these results imply that ER $\beta$ suppresses c-FLIP transcriptional activity possibly by competing with Sp1 and Sp3. Biological relevance of $5 \alpha-\mathrm{DHT}$ or $2-\mathrm{ME}_{2}-$ mediated suppression of c-FLIP activation was determined by examining the effect of $5 \alpha$-DHT on cell growth and apoptosis in the presence and absence of 2-ME 2 . Treatment with $5 \alpha$-DHT significantly decreased colonyforming ability of DU145 cells. Decreased colony forming ability was further reduced in the presence of $2-\mathrm{ME}_{2}$ (Fig. 4B). Immunoblot analysis revealed dose-dependent

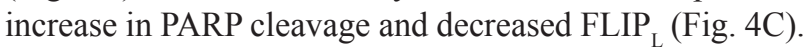
These observations suggest that ER $\beta$ can inhibit growth of androgen-independent prostate cancer cells through transcriptional downregulation of c-FLIP and activation of apoptosis.

We analyzed the expression of $\mathrm{Sp} 1$ and $\mathrm{Sp} 3$ in human prostate tissues by immunohistochemistry (IHC). IHC analysis revealed significantly elevated Sp1 expression (27/35 human prostate tumors; $p=0.035)$ with no detectable expression in the normal tissue (Fig. 5A and Table 1). However, differences in Sp3 expression 


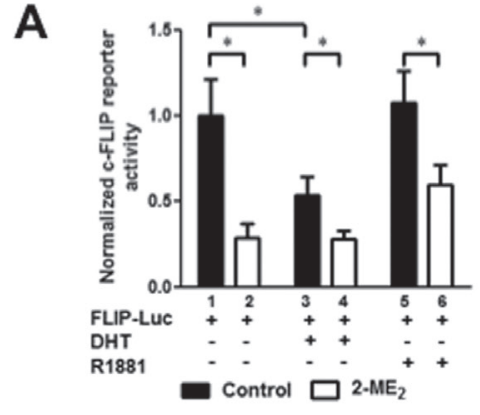

C



$\mathbf{E}$
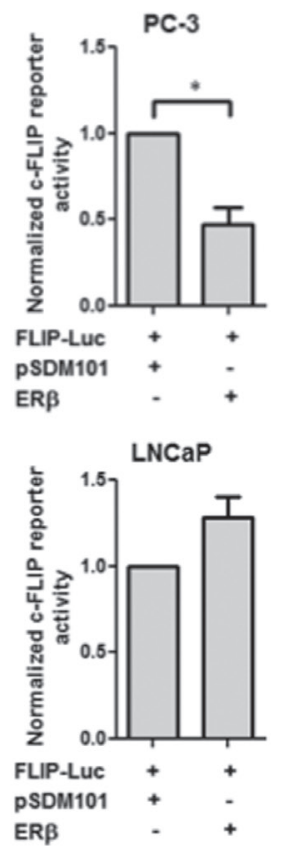
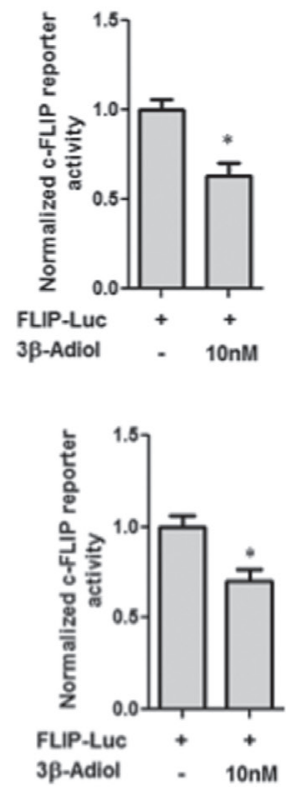



D
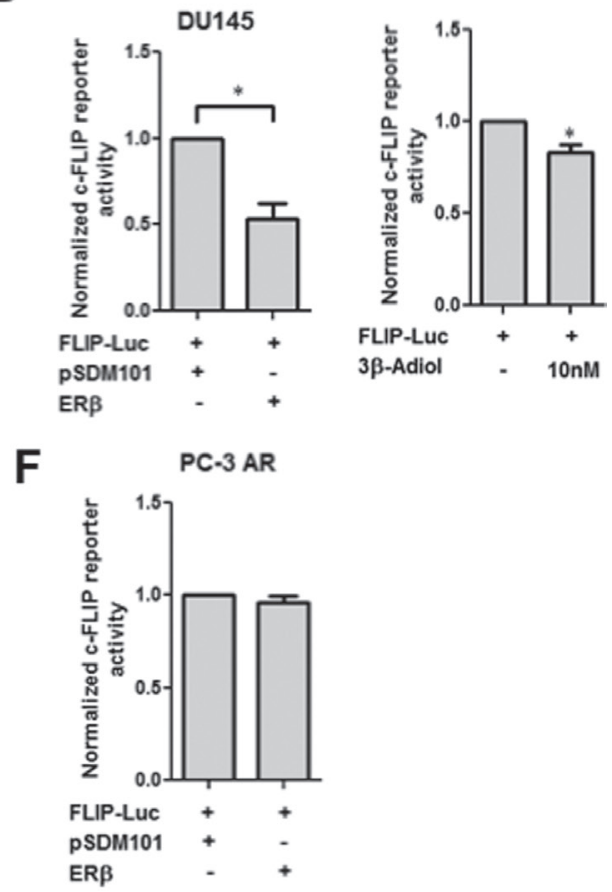

Figure 3: Androgen metabolism regulates c-FLIP transcriptional activity. A. $5 \alpha$-DHT but not R1881 inhibits c-FLIP promoter activity. DU145 cells were transfected with c-FLIP reporter plasmid $(0.5 \mu \mathrm{g})$. Post-transfection, cells were serum-starved for additional $24 \mathrm{~h}$, treated with 2-ME $(5 \mu \mathrm{M})$ for $24 \mathrm{~h}$ and then stimulated with $5 \alpha$-DHT or R1881 $(1 \mathrm{nM})$ for $1 \mathrm{~h}$. Luciferase activity was determined. Error bars represent \pm S.E.M $(n=3) .{ }^{*} p<0.05$ (Student's $t$-test). B. Binding of $\mathrm{Sp} 1$ and $\mathrm{Sp} 3$ to the endogenous c-FLIP promoter stimulated with DHT or R1881 in the presence or absence of 2-ME . After stimulation with $5 \alpha$-DHT or R1881 $(1 \mathrm{nM})$ for $1 \mathrm{~h}$ and/or treatment with 2-ME for $24 \mathrm{~h}$, ChIP-qPCR was performed using anti-Sp1 or anti-Sp3 antibody in DU145 cells. The amplification value from immunoprecipitated DNA was normalized to $10 \%$ input. Error bars represent \pm S.E.M. $(n=3) .{ }^{*} p<0.05$. C. AKR1C1 and ER $\beta$ mRNA expression in DU145 cells treated with $5 \alpha$-DHT or $2-\mathrm{ME}_{2}$. Total RNA was isolated from cells treated with $5 \alpha-\mathrm{DHT}$ or R1881 (1 nM) for $1 \mathrm{~h}$, or with 2-ME $(5 \mu \mathrm{M})$ for $24 \mathrm{~h}$. PCR reactions were conducted in triplicate, and relative mRNA expression was normalized to $\beta$-actin. Error bars represent \pm S.D. $(n=3) .{ }^{*} p<0.05$. D-F. ER $\beta$ regulates c-FLIP in prostate cancer cells. pGL3-FLIP $(-121 /+242)$-Luc plasmid was co-transfected along with empty vector (pSDM101) or expression plasmids for ER $\beta(0.5 \mu \mathrm{g} / \mathrm{well})$. Post-transfection, cells were treated with 2-ME ${ }_{2}$ for $24 \mathrm{~h}$ and luciferase activity was measured. In addition, cells were transfected with pGL3-FLIP $(-121 /+242)$-Luc plasmid and treated with different concentration of 3 $\beta$-Adiol. Panels D, E, and F represent DU145, PC-3 (Fig. 3E top panel), LNCaP (Fig. 3E bottom panel) and PC-3 AR (PC-3 cells stably expressing AR) cells respectively. Data presented is average \pm S.E.M of three independent experiments conducted in triplicate. ${ }^{*} p<0.05$. 
A

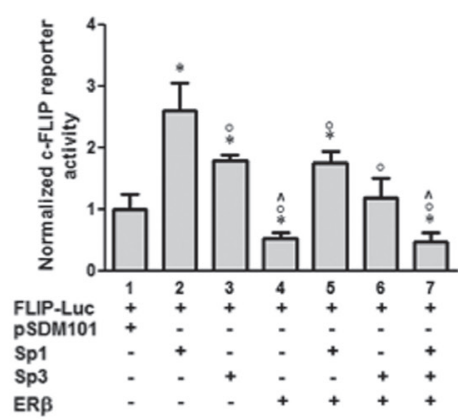

C

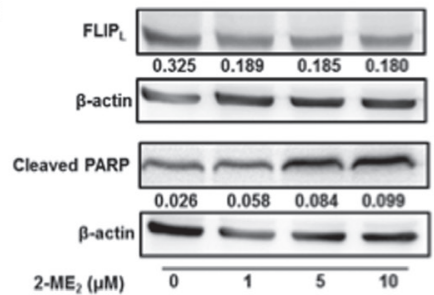

B

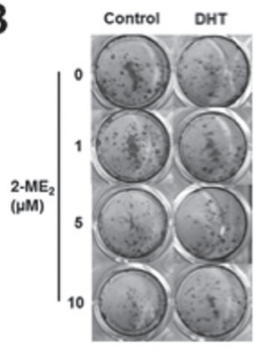

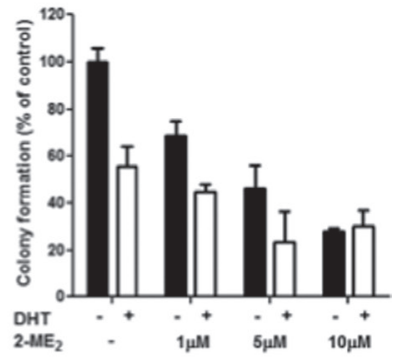

Figure 4: Non-genomic regulation of c-FLIP by ERß. A. ER $\beta$ suppresses $S p 1$ and Sp3-mediated transactivation of c-FLIP in DU145 cells. Transient expression was conducted as described in materials and method using pGL3-FLIP (-121/+242)-Luc plasmid in the presence and absence of expression plasmids for Sp1, Sp3 or ER $\beta$. Where indicated cells were co-transfected with expression plasmids for $\mathrm{Sp} 1, \mathrm{Sp} 3$ or ER $\beta$ or all three $\left(0.5 \mu \mathrm{g} /\right.$ well of each) and total amount of DNA was maintained constant using pcDNA3.1. $\left({ }^{*} p<0.05\right.$; *compared to pSDM101 control, ${ }^{\circ}$ compared to Sp1, and ^ compared to Sp3). B. Colony forming ability of DU145 cells stimulated with $5 \alpha$-DHT. DU145 cells were seeded in 24-well plates at a density of 100 cells per well in triplicate in $1 \mathrm{~mL}$ of growth media and stained with crystal violet after treating with $5 \alpha-\mathrm{DHT}(1 \mathrm{nM})$ for $1 \mathrm{~h}$ and $2-\mathrm{ME}_{2}$ for $24 \mathrm{~h}$ (Left), and colonies were counted (Right). Error bars indicate \pm S.D. $(n=3)$. C. $2-\mathrm{ME}_{2}$ induces apoptosis in DU145 cells. Whole cell extracts prepared from cells treated with increasing concentration of $2-\mathrm{ME}_{2}(1,5$, and $10 \mu \mathrm{M})$ were used in immunoblotting with antibodies for cleaved PARP (48 h) and FLIP $(12 \mathrm{~h}) . \beta$-actin was used as a loading control. Numbers indicate ratio of c-FLIP or c-PARP with respect to $\beta$-actin loading control.

did not reach statistical significance (Table 1). We also compared the expression of AKR1C1, c-FLIP, Sp1, Sp3 and ER $\beta$ in human prostate tumors and normal tissue from oncomine, cancer-profiling database. In silico analysis of these data from two different cohorts revealed significantly upregulated expression of $\mathrm{Sp} 1$ and c-FLIP in human prostate tumors compared to normal tissue (Fig. 5B). On the other hand, expression of AKR1C1, ER $\beta$ and Sp3 was down regulated (Fig. 5C).

\section{DISCUSSION}

Recent evidence shows the importance of androgen metabolism in the progression of prostate cancer to castrate-resistant state. Here, we show for the first time that AKR1C1 can contribute to CRPCA by inhibiting apoptosis through ER $\beta$-mediated transcriptional suppression of c-FLIP. The tumor suppressive role for ER $\beta$ has been reported using in vitro cell culture and in vivo animal models [6-10]. It has also been reported that human prostate cancer cells express both ER $\alpha$ and $\beta$ and ER $\beta$ knockout mice develop HGPIN lesions [9]. Furthermore, in silico analysis revealed significantly decreased expression of both AKR1C1 and ER $\beta$ in human prostate tumors compared to normal tissue. Therefore, our data demonstrating tumor suppressor role for ER $\beta$ is in agreement with these published findings.

Additionally, we provide evidence that ER $\beta$ inhibits apoptosis non-genomically by competing with $\mathrm{Sp} 1$ and $\mathrm{Sp} 3$ to transcriptionally downregulate c-FLIP. Given the lack of understanding how ER $\beta$ activation inhibits apoptosis to drive prostate pathogenesis, our observations are novel. Estrogen receptors (ERs) regulate gene expression either classically by binding to estrogen response element (ERE) in the promoter regions or non-classically in association with other transcription factors including AP-1, Sp1 and NFKB [22]. Genome-wide global profiling of ER $\beta$ occupancy studies indicate that ERE is not the major binding site for ER $\beta$, but it can bind to sites including Sp1 [23]. Data presented in this manuscript provide evidence that 2-ME 2 (i) inhibits $\mathrm{Sp} 1$ transactivation of c-FLIP; (ii) activates ER $\beta$ in a dose-dependent manner and (iii) that ectopic expression of ER $\beta$ or treatment with its ligand $3 \beta$-Adiol suppresses c-FLIP promoter activity despite lack of consensus ERE. The observed downregulation of c-FLIP is associated with induction of apoptosis in prostate cancer cells. Based on these observations, we speculate that ER $\beta$ downregulates c-FLIP either directly by binding to $\mathrm{Sp} 1$ sites on the c-FLIP promoter or by modulating the ratio of $\mathrm{Sp} 1 / \mathrm{Sp} 3$ through competitive 
A

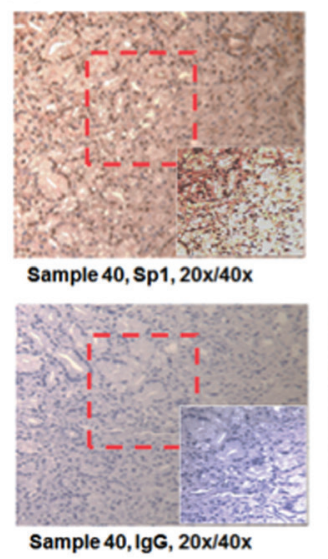

Sample 40, IgG, 20x/40x
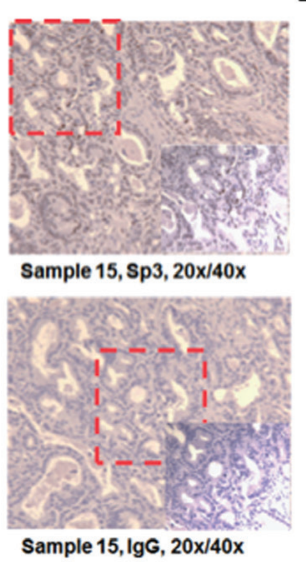

B
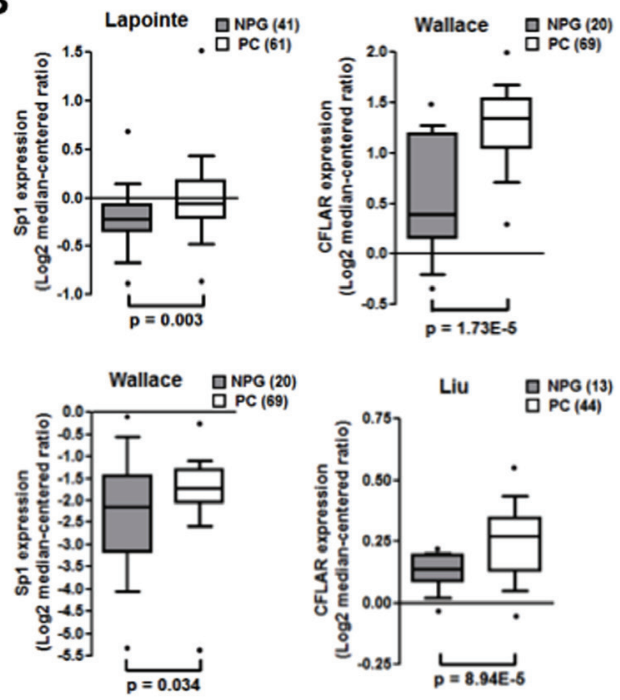

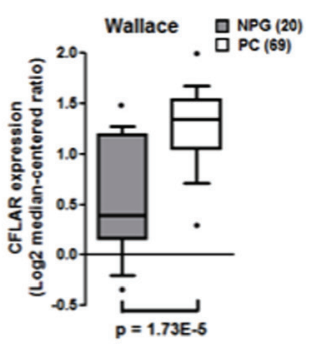

C
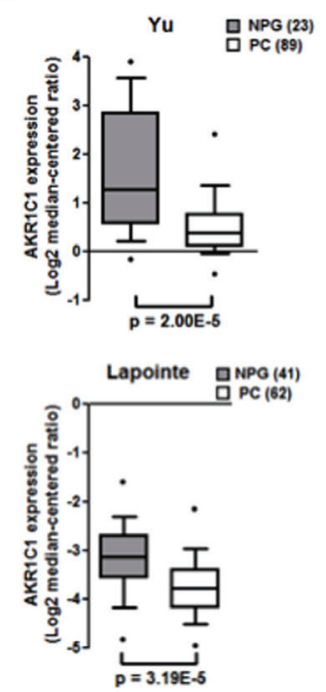
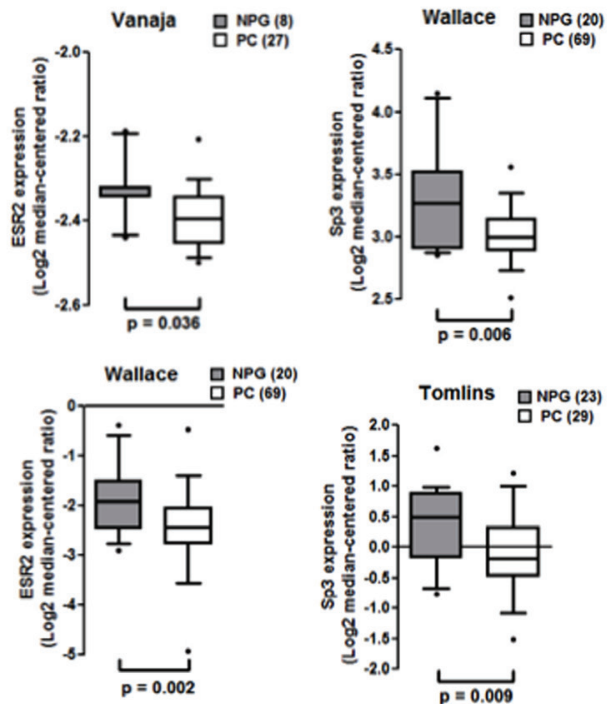

Figure 5: Expression of Sp1, Sp3, c-FLIP, AKR1C1 and ERß in human prostate tumors. A. Human prostate tissue array containing 80 tissue cores (duplicated tissues from 40 individual donors) obtained from Cybridi, Inc. was used in immunohistochemical evaluation using antibodies against Sp1, Sp3 (sc-28305) and negative control IgG. Representative picture at different magnifications is shown. B. Box plots of in silico analysis of expression of Sp1 (left panels) and c-FLIP (right panels) in human prostate cancer and normal prostate tissues. Oncomine microarray data retrieved from two independent cohorts was used. C. Box plots of in silico analysis of expression of AKR1C1, ER $\beta$ and Sp3 expression (left, middle and right panels) in human prostate cancer and normal prostate tissues. (NPG: normal prostate gland, PC: prostate carcinoma).

DNA binding. Alternatively, involvement of other ER $\beta$ coregulators cannot be ruled out. Additionally, it is also possible that 2-ME $-\mathrm{ME}_{2}$-treatment can activate epigenetically silenced ER $\beta$ through demethylation. It has been reported that due to methylation of the ER $\beta$ promoter, relative $\mathrm{ER} \beta$ expression is undetectable in $\mathrm{LNCaP}$ and very low in DU145 cells compared to PC-3 cells [26]. Since our results show that treatment with 2-ME $\mathrm{ME}_{2}$ resulted in dosedependent increased ER $\beta$ expression in DU145 cells they signify the possibility that $2-\mathrm{ME}_{2}$-treatment can activate epigenetically silenced ER $\beta$ through demethylation, which will be a focus of our future studies. Taken together, these observations for the first time suggest that loss of ER $\beta$ can contribute to aggressive advanced prostate cancer through transcriptional regulation of c-FLIP.

$\mathrm{Sp} 1$ and $\mathrm{NF} \kappa \mathrm{B}$ are transcription factors that regulate expression of genes involved in various cellular processes of oncogenesis including differentiation, apoptosis, cell migration, and cell cycle progression [27, 28]. Moreover, published studies show correlation between elevated levels of NFKB in castrate-resistant prostate tumors and disease progression [29]. However, to the best of our 
Table 1: Quantitative analysis of immunohistochemical evaluation of Sp1 and Sp3. Immunohistochemical staining was performed essentially as described in methods. The staining results were scored blindly and semi quantitatively based on staining intensities and proportion of positive staining tumor cells. Briefly, the proportion of positive tumor cells was scored as follows: 0, no stained cells; $1,1-50 \% ; 2,50-100 \%$ positive staining. The intensity score represents the average staining intensity of tumor cells: +, mild; ++, weak; +++, strong intensity. The statistical significance was calculated using Pearson Chi-Square test.

\begin{tabular}{|c|c|c|c|c|c|}
\hline & & Negative & Positive & Total & Pearson Chi-Square \\
\hline Normal & Sp1 & 3 & 0 & 3 & \multirow{3}{*}{ Value $7.995 p=0.035$} \\
\hline Carcinoma & & 8 & 27 & 35 & \\
\hline Total & & 11 & 27 & 38 & \\
\hline Normal & Sp3 & 0 & 0 & 0 & \multirow{3}{*}{ Value $1.327 p=0.249$} \\
\hline Carcinoma & & 23 & 11 & 34 & \\
\hline Total & & 23 & 11 & 34 & \\
\hline
\end{tabular}

knowledge no studies have examined the expression of Sp1 and Sp3 in human prostate tumors. The current study for the first time demonstrates elevated expression of $\mathrm{Sp} 1$ in human prostate tumors compared to normal tissue. These observations are consistent with published studies in other tumor types [30-32]. For example, in comparison to normal tissues or cells Sp1 levels are higher in breast, thyroid, hepatocellular, pancreatic, colorectal, gastric and lung cancer. In addition, abnormal Sp1 levels are highly correlated with stage and poor prognosis of cancer [31].

Our data also shows potential combinatorial effects of $\mathrm{Sp} 1$ with $\mathrm{AR}, \mathrm{Sp} 3$ and $\mathrm{p} 65$ in the regulation of c-FLIP transcription. Treatment with pro-apoptotic agent $2-\mathrm{ME}_{2}$ also blocked the observed effects. Sp1 and Sp3 both bind GC-rich sequences and regulate gene expression either thorough cooperative interactions or inhibitory interactions whereby $\mathrm{Sp} 3$ can decrease $\mathrm{Sp} 1$ transactivation. Furthermore, published evidence demonstrates that Sp1 can also regulate gene expression in association with ligand activated and orphan nuclear receptors including $\mathrm{AR}, \mathrm{ER}$, progesterone receptor $(\mathrm{PR})$ and retinoic acid receptor (RAR). Sp1 and/or Sp3 also cooperatively activate gene expression through interaction with other transcription factors including E2F, SMADs, NFкB, GATA and c-Jun [28]. Previous studies have demonstrated association between Sp1 and AR. For example, it has been shown that despite lack of consensus ARE, AR can transactivate $\mathrm{p} 21$ by binding to $\mathrm{Sp} 1$ sequence elements in association with $\mathrm{Sp} 1$ in response to androgens [33]. In addition, Sp1 stimulates AR target gene PSA through its transcriptional activation ability. Inhibition or knocking down of Sp1 to normal cellular level has been reported to decrease tumor formation, growth and metastasis [34-37]. For example, chemopreventive agents including Betulinic acid and Curcumin reduce the expression of $\mathrm{Sp} 1$ and Sp3 with consequent reduced expression of their target genes including EGFR, Cyclin D1, VEGF and SREB2. Mithramycin A and tolfenamic acid together reduce Sp1 levels in pancreatic cancer cells. Thus, interactions between $\mathrm{Sp} 1$ and other proteins can differentially affect Sp1-dependent transactivation depending on the promoter context [27, 28]. In agreement with these published findings, our work demonstrates that $2-\mathrm{ME}_{2}$-mediated restoration of ER $\beta$ prevents Sp1 or p65 recruitment or combination of both $\mathrm{Sp} 1$ and $\mathrm{p} 65$ to c-FLIP promoter with consequent induction of apoptosis. In future studies, we will determine whether binding of $\mathrm{Sp} 1$ facilitates recruitment of NFKB or vice versa.

Surprisingly, the current study also observed that treatment with metabolizable androgens such as $5 \alpha$-DHT but not non-metabolizable R1881 lowers enrichment of $\mathrm{Sp} 1$ and increase enrichment of Sp3 to the c-FLIP promoter leading to reduced transcriptional activation and inhibition of colony formation in DU145 cells. How might treatment with $5 \alpha$-DHT in AR negative cells contribute to growth suppression? AKR family members including AKR1C1, C2 and C3 function as $3-, 17-$ and 20-ketoseteroid reductases respectively to form $3-\alpha / \beta, 17-\beta$ and $20-\alpha$-hydroxyl metabolites $[21,38]$. For example, inactivation of $5 \alpha$-DHT by AKR1C1 results in the formation of 3 $\beta$-Adiol, a potent ER $\beta$ ligand [21]. Interestingly, the intraprostatic levels of $3 \beta$-Adiol, was reported to be 100-fold higher than estradiol [21]. Data presented here shows (i) expression of AKR1C1 decreases in human prostate tumors, (ii) $5 \alpha$-DHT enhances AKR1C1 expression; (iii) both $3 \beta$-Adiol and ER $\beta$ suppress c-FLIP activation in DU145 and PC-3 cells but not in LNCaP cells. It is noteworthy to mention that PC-3 cells are more sensitive to $3 \beta$-Adiol, which could be related to relatively higher expression of ER $\beta$ as it is unmethylated. These observations are consistent with the hypothesis that variations in the intraprostatic levels of $3 \beta$-Adiol 
can potentially dictate the outcome of AR/ER signaling and possibly the disparate increased risk of CRPCA by preventing apoptosis via c-FLIP. Hypothetical model is shown in Fig. 6. In future studies, we will determine the crosstalk between ER $\beta$ and androgen metabolism and how other nuclear receptors including ER $\alpha$ impact the biological outcome.

Prostate cancer is the second leading cause of cancer related deaths in men. Localized cancer can be treated effectively either by surgery or radiation [39]. The first line therapy, ADT though initially effective, progresses to castrate-resistant disease in a majority of patients [40]. There are no effective curative approaches for treatment of castrate-resistant disease. It is well accepted that AR is activated in about $80 \%$ of castrate-resistant tumors [41]. Several mechanisms including AR amplification/ overexpression, alteration in cofactors or AR variants and crosstalk with signal transduction pathways plays a critical role in the reactivation of $\operatorname{AR}[42,43]$. In addition, emerging evidence demonstrates survival benefit and tumor growth inhibition in patients by suppression of adrenal androgen production by abiraterone acetate suggests a pivotal role for intratumoral androgen metabolism [44]. Similarly, enzalutamide, which provides survival benefit directly, inhibits AR activation [45]. Although these data provide convincing evidence that androgen metabolism and $\mathrm{AR}$ are critical targets for CRPC progression, resistance to these agents is a major challenge for management of
CRPC. This is substantiated by recent data demonstrating reactivation of glucocorticoid receptor (GR) as a prevalent mechanism of acquired resistance to enzalutamide [46]. Data presented in this manuscript provided evidence for targeting c-FLIP either by increasing the levels of AKR1C1 or activating ER $\beta$ could have therapeutic potential. Do changes in AKR1C1 lead to increase in c-FLIP expression during CRPCA progression? How do interactions among transcription factors $\mathrm{Sp} 1 / \mathrm{Sp} 3 / \mathrm{NF} \kappa \mathrm{B} / \mathrm{AR}$ involved in upregulation of c-FLIP contribute to CRPCA? Taken together, these observations clearly indicate a conjectural role for $\mathrm{AKR} 1 \mathrm{C} 1 / \mathrm{ER} \beta / \mathrm{c}-\mathrm{FLIP}$ in prostate pathogenesis that warrants additional investigations to elucidate the regulation of c-FLIP with respect to androgen metabolism and progression to CRPC. Furthermore, despite its ability to exert anti-neoplastic activity in variety of tumor types, $2-\mathrm{ME}_{2}$ was found to be clinically non-viable [47]. The data presented in this manuscript justifies investigations combining 2- $\mathrm{ME}_{2}$ with $\mathrm{ER} \beta$ agonists or $3 \beta$-Adiol for effective management of CRPC.

\section{MATERIALS AND METHODS}

\section{Cell lines and reagents}

AR-positive androgen dependent (LNCaP), ARnegative androgen independent (PC-3 and DU145) human prostate cancer cells were purchased from American Type

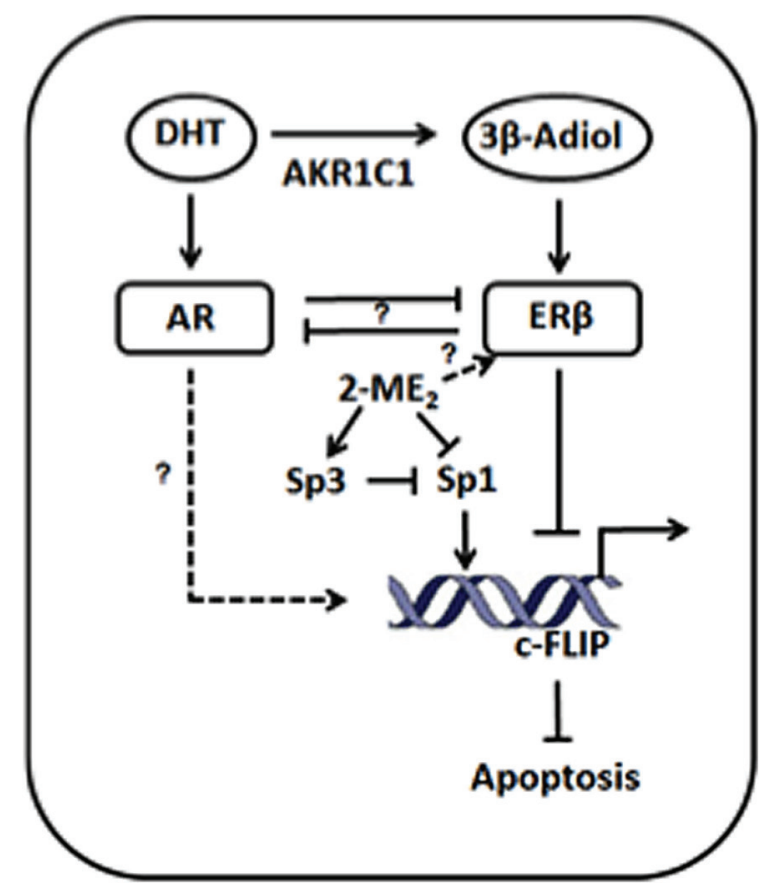

Figure 6: Hypothetical model. Hypothetical model of ER $\beta$-mediated transcriptional inhibition of c-FLIP. AKRC1 mediated inactivation of $5 \alpha$-DHT generates 3- $\beta$-Adiol, a potent ligand for ER $\beta$. Activation of ER $\beta$ by 3- $\beta$-Adiol down regulates c-FLIP transcriptionally possibly by regulating the binding of Sp and NFKB factors to the c-FLIP promoter. Furthermore, $5 \alpha$-DHT-induced activation of AR could potentially suppress ER $\beta$-mediated transcriptional suppression of c-FLIP activation. 
Culture Collection (Manassas, VA); and AR-positive androgen independent (C4-2B) were obtained from Dr. Thambi Dorai (Department of Biochemistry and Molecular Biology, New York Medical College, NY). All cells were grown essentially as described previously [18]. Logarithmically growing $\mathrm{LNCaP}, \mathrm{PC}-3$ and $\mathrm{C} 4-2 \mathrm{~B}$ $(3 \mu \mathrm{M})$ and DU145 $(5 \mu \mathrm{M})$ cells were treated with 2-methoxyestradiol $\left\{2-\mathrm{ME}_{2}\right.$; obtained from Sigma-Aldrich (St. Louis, MO)\}.

\section{Western blot analysis and quantitative real time PCR}

Western blot and qRT-PCR analysis was conducted as described previously [18]. Primary antibodies used include FLIP $_{L}$ (generated in-house), Cleaved PARP (9541S; Cell signaling, Danvers, MA), and $\beta$-actin (A5316; Sigma-Aldrich, St. Louis, MO). Bound antibody was visualized using ECL kit (Thermo Fisher Scientific, Waltham, MA). All the blots were stripped and reprobed with $\beta$-actin to ensure equal loading of protein. Images were captured and analyzed using Gene snap software (Syngene, Frederick, MD), and quantification was carried out using Gene tools software (Syngene, Frederick, MD).

Total cellular RNA isolated using Trizol reagent (Invitrogen, Grand Island, NY) according to the manufacturer's instructions. Target genes were amplified and expression was measured using 7300 Applied Biosystems with SYBR Green dye. The primers used were as follows: $\beta$-actin, forward 5'-GGCACCCAGCACAATGAAGATCA-A-3' and reverse 5'-TAGAAGC-ATTTGCGGTGGACGATG-3'; AKR1C1, forward 5'-GCTTTAGAGGCCACCAA-ATTGGCA-3' and reverse 5'-ACTGCCATCTGCAATCTTGCTTCG-3'; $\mathrm{ER} \beta$, forward 5'-GGCACCTTTCTCCTT-TAGTG-3' and reverse 5'-GGTGTGTTCTAGCGATCTTG-3'. PCR reactions were conducted in triplicate, and relative mRNA expression was normalized to $\beta$-actin. Fold change in experiments was determined relative to solvent control group. Specific amplification of target genes was validated using a dissociation curve.

\section{Transient transfection}

For transfections, human prostate cancer cells were plated in triplicate at a density of 100,000 cells per well in 24-well plates. Cells were transfected with indicated c-FLIP reporter plasmids $(0.5 \mu \mathrm{g})$ along with Renilla luciferase (10 ng) using Lipofectamine 2000 reagent (Invitrogen, Grand Island, NY) according to the manufacturer's recommendations. For co-transfection experiments, $0.5 \mu \mathrm{g} /$ well of Sp1, Sp3, and/or ER $\beta$ was used along with $-121 /+242$ sequence of c-FLIP reporter plasmid. Total amount of DNA was maintained constant using backbone vector pcDNA3.1. Where necessary, cells were treated with or without $2-\mathrm{ME}_{2}$ for $24 \mathrm{~h}$ and luciferase activity was determined using Dual Luciferase Reporter Assay system (Promega, Madison, WI).

\section{Electrophoretic mobility shift assay (EMSA) and chromatin immunoprecipitation (ChIP)}

EMSA and ChIP were essentially conducted as described previously [13, 19]. For EMSA, Nuclear extracts prepared from LNCaP, C4-2B, and PC-3 cells treated with $2-\mathrm{ME}_{2}$ for $24 \mathrm{~h}$ were used in EMSA experiments using ${ }^{32} \mathrm{P}$-labeled c-FLIP promoter sequence oligonucleotide $(+64 /+89)$ containing overlapping binding sites for Sp1, Sp3, p65 and AR. For competition experiments, the radiolabeled probe was mixed with 100fold molar excess of unlabeled double-stranded synthetic c-FLIP oligonucleotide for $5 \mathrm{~min}$ prior to the addition of nuclear extracts. For super-shift experiments, nuclear extracts were pre-incubated with Sp1, Sp3, p65, p50, AR or control $\mathrm{IgG}$ antibodies for $30 \mathrm{~min}$ on ice prior to use in EMSA. For ChIP, sheared, cross-linked protein-DNA fragments were immunoprecipitated with normal rabbit IgG (sc-2027), anti-Sp1 (sc-59 X) anti-Sp3 (sc-644 X) antibody, or anti-p65 antibody (sc-372 X; obtained from Santa Cruz Biotechnology, Santa Cruz, CA) and immune complexes were absorbed with protein $\mathrm{G}$ magnetic beads (Active Motif, Carlsbad, CA). 10\% of the input extract was saved as input control for normalization before adding antibody for immunoprecipitation. Cross-linking was then reversed, and immunoprecipitated DNA was amplified by PCR or quantitative PCR. PCR products were resolved on $3 \%$ agarose gel. Densitometry was used to quantify the PCR products and the results were normalized to respective input values. For qPCR, triplicate PCR reactions were performed for each sample and the data are presented as the average \pm S.E.M. and the results were normalized to respective input values. Fold enrichment was calculated as $100 * 2^{-(\text {Ct }[\text { Target }]-C t[\text { Input })}$.

\section{Clonogenic cell survival assay}

For colony formation, DU145 cells seeded in 24-well plates at a density of 100 cells per well in $1 \mathrm{ml}$ of media were treated with $2-\mathrm{ME}_{2}$ for $24 \mathrm{~h}$ in the presence or absence of DHT (1 nM towards final $1 \mathrm{~h}$ of $24 \mathrm{~h}$ treatment). Following this treatment, cells were washed with PBS and media was replaced with fresh media with no treatment. Following one week, cells were fixed with ice-cold $100 \%$ methanol and stained with $0.5 \%$ crystal violet in $20 \%$ methanol, and groups in excess of 15 cells were counted as colonies.

\section{Immunohistochemical evaluation of Sp1 and Sp3 in human prostate tumors}

Human prostate tissue array containing 80 tissue cores (duplicated tissues from 40 individual 
donors) obtained from Cybridi, Inc. was used in immunohistochemical evaluation. Antibodies for Sp1 (sc-59) and Sp3 (sc-28305) and negative control IgG antibody obtained from (Santa Cruz Biotechnology, Santa Cruz, CA) and (Southern Biotechnology, Cat\# 0111-01) respectively were used in immunohistochemical evaluation. Immunohistochemical staining and evaluation was performed by Cybridi, Inc. The staining results were scored blinded and semi quantitatively based on staining intensities and proportion of positive staining tumor cells. Briefly, the proportion of positive tumor cells was scored as follows: 0 , no stained cells; $1,1-50 \% ; 2,50-100 \%$ positive staining. The intensity score represents the average staining intensity of tumor cells: + , mild; ++ , weak; +++ , strong intensity. The statistical significance was calculated using Pearson Chi-Square test.

\section{Oncomine data}

Sp1, Sp3, c-FLIP, ER $\beta$, and AKR1C1 expression in normal prostate gland and prostate carcinoma were obtained from two independent studies for each gene expression in the Oncomine database. Primary sources are from different group's microarray data mentioned in the graph (http://www.oncomine.org). Data sets are log transformed and illustrated as median centered box plots between the differences of mRNA transcription within cohorts. Statistical significance was determined by a two-tailed Mann-Whitney test. Detailed information of the standardized normalization and statistical calculations are indicated on the Oncomine website.

\section{Statistical analysis}

All numerical results are expressed as mean \pm S.D. or S.E.M. derived from 3 independent experiments, unless otherwise stated. Statistical analyses were conducted using Student's $t$-test and statistically significant differences were established as $p<0.05$. The statistical significance of IHC data was calculated using Pearson Chi-Square test.

\section{ACKNOWLEDGMENTS}

This work was supported in part by funds from National Cancer Institute R01 CA 135451; National Center for Complementary and Alternative Medicine AT 005513-01A1, AT 007448-01; Veterans Affairs-Merit Award 1 I01 BX 000766-01(APK) and 1 R01 CA 149516 (RG). We sincerely thank Dr Rong Li, Department of Molecular Medicine, The University of Texas Health Science Center at San Antonio for providing the ER $\beta$ expression plasmid used in this work. We acknowledge support provided by Cancer Therapy and Research Center at The University of Texas Health Science Center at San Antonio through the National Cancer Institute support grant \#2P30 CA 054174-17 (APK and RG).

\section{REFERENCES}

1. Cetin K, Li S, Blaes AH, Stryker S, Liede A, Arneson TJ. Prevalence of patients with nonmetastatic prostate cancer on androgen deprivation therapy in the United States. Urology. 2013; 81:1184-9.

2. Loblaw DA, Walker-Dilks C, Winquist E, Hotte SJ. Genitourinary cancer disease site group of cancer care Ontario's program in evidence-based care. Systemic therapy in men with metastatic castration-resistant prostate cancer: A systematic review. Clinical Oncology. 2013; 25:406-30.

3. Cornforth AN, Davis JS, Khanifar E, Nastiuk KL, Krolewski JJ. FOXO3a mediates the androgen-dependent regulation of FLIP and contributes to TRAIL-induced apoptosis of LNCaP cells. Oncogene. 2008; 27:4422-33.

4. Ricke WA, Wang Y, Cunha GR. Steroid hormones and carcinogenesis of the prostate: the role of estrogens. Differentiation. 2007; 75:871-882.

5. Savoy RM, Ghosh PM. The changing roles of steroid nuclear receptors with prostate cancer progression. Endocr Relat Cancer. 2013; 20:C9-11.

6. Leung YK, Mak P, Hassan S, Ho SM. Estrogen receptor (ER)-beta isoforms: a key to understanding ER-beta signaling. Proc Natl Acad Sci USA. 2006; 103:13162-13167.

7. Dey $\mathrm{P}$, Ström A, Gustafsson JÅ. Estrogen receptor $\beta$ upregulates FOXO3a and causes induction of apoptosis through PUMA in prostate cancer. Oncogene. 2014; 33:4213-25.

8. Hussain S, Lawrence MG, Taylor RA, Lo CY, Frydenberg M, Ellem SJ, Furic L, Risbridger GP. Estrogen receptor $\beta$ activation impairs prostatic regeneration by inducing apoptosis in murine and human stem/progenitor enriched cell populations. PLoS One. 2012; 7:e40732.

9. McPherson SJ, Hussain S, Balanathan P, Hedwards SL, Niranjan B, Grant M, Chandrasiri UP, Toivanen R, Wang Y, Taylor RA, Risbridger GP. Estrogen receptor-beta activated apoptosis in benign hyperplasia and cancer of the prostate is androgen independent and TNFalpha mediated. Proc Natl Acad Sci USA. 2010; 107:3123-3128.

10. Paruthiyil S, Parmar H, Kerekatte V, Cunha GR, Firestone GL, Leitman DC. Estrogen receptor beta inhibits human breast cancer cell proliferation and tumor formation by causing a G2 cell cycle arrest. Cancer Res. 2004; 64:423-8.

11. Gong J, Kumar SA, Graham G, Kumar AP. FLIP: molecular switch between apoptosis and necroptosis. Mol Carcinog. 2014; 53:675-85. 
12. Mahmoud AM, Yang W, Bosland MC. Soy isoflavones and prostate cancer: a review of molecular mechanisms. J Steroid Biochem Mol Biol. 2014; 140:116-32.

13. Ganapathy $M$, Ghosh $R$, Jianping $X$, Zhang $X$, Bedolla R, Schoolfield J, Yeh IT, Troyer DA, Olumi AF, Kumar AP. Involvement of FLIP in 2-methoyxestradiolinduced tumor regression in transgenic adenocarcinoma of mouse prostate model. Clinical Cancer Research. 2009; 15:1601-11.

14. Garcia GE, Wisniewski HG, Lucia MS, Arevalo N, Slaga TJ, Kraft SL, Strange R, Kumar AP. 2-methoxyestradiol inhibits prostate tumor development in transgenic adenocarcinoma of mouse prostate: role of tumor necrosis factor-alpha-stimulated gene 6. Clinical Cancer Research. 2006; 12:980-8.

15. Zhang Q, Ma Y, Cheng YF, Li WJ, Zhang Z, Chen SY. Involvement of reactive oxygen species in 2-methoxyestradiol-induced apoptosis in human neuroblastoma cells. Cancer Letter. 2011; 313:201-10.

16. Verenich S, Gerk PM. Therapeutic promises of 2-methoxyestradiol and its drug disposition challenges. Mol Pharm. 2010; 7:2030-9.

17. Mueck AO, Seeger H. 2-methoxyestradiol-biology and mechanism of action. Steroids. 2010; 75:625-31.

18. Li G, Rivas P, Bedolla R, Thapa D, Reddick RL, Ghosh R, Kumar AP. Dietary resveratrol prevents development of highgrade prostatic intraepithelial neoplastic lesions: involvement of SIRT1/S6K axis. Cancer Prev Res. 2013; 6:27-39.

19. Gong J, Xie J, Bedolla R, Rivas P, Chakravarthy D, Freeman JW, Reddick R, Kopetz S, Peterson A, Wang H, Fischer SM, Kumar AP. Combined targeting of STAT3/ $\mathrm{NF}-\kappa \mathrm{B} / \mathrm{COX}-2 / \mathrm{EP} 4$ for effective management of pancreatic cancer. Clin Cancer Res. 2014; 20:1259-73.

20. Gao S, Lee P, Wang H, Gerald W, Adler M, Zhang L, Wang YF, Wang Z. The androgen receptor directly targets the cellular Fas/FasL-associated death domain protein-like inhibitory protein gene to promoter the androgen-independent growth of prostate cancer cells. Mol Endocrinol. 2005; 19:1792-802.

21. Rižner TL, Penning TM. Role of aldo-keto reductase family 1 (AKR1) enzymes in human steroid metabolism. Steroids. 2013; 79:49-63.

22. Thomas C, Gustafsson JA. The different roles of ER subtypes in cancer biology and therapy. Nat Rev Cancer. 2011; 11:597-608.

23. Zhao C, Gao H, Liu Y, Papoutsi Z, Jaffrey S, Gustafsson JÅ, Dahlman-Wright K. Genome-wide mapping of estrogen receptor-beta-binding regions reveals extensive crosstalk with transcription factor activator protein-1. Cancer Research. 2010; 70:5174-83.

24. McPherson SJ, Hussain S, Balanathan P, Hedwards SL, Niranjan B, Grant M, Chandrasiri UP, Toivanen R, Wang Y, Taylor RA, Risbridger GP. Estrogen receptor-beta activated apoptosis in benign hyperplasia and cancer of the prostate is androgen independent and TNFalpha mediated. Proc Natl Acad Sci USA. 2010; 107:3123-3128.

25. Paruthiyil S, Parmar H, Kerekatte V, Cunha GR, Firestone GL, Leitman DC. Estrogen receptor beta inhibits human breast cancer cell proliferation and tumor formation by causing a G2 cell cycle arrest. Cancer Res. 2004; 64:423-8.

26. Zhu X, Leav I, Leung YK, Wu M, Liu Q, Gao Y, McNeal JE, Ho SM. Dynamic regulation of estrogen receptor-beta expression by DNA methylation during prostate cancer development and metastasis. Am J Pathol. 2004; 164:2003-12.

27. Archer MC. Role of Sp transcription factors in the regulation of cancer cell metabolism. Genes \& Cancer. 2011; 2:712-9.

28. Safe S, Abdelrahim M. Sp transcription factor family and its role in cancer. Eur J Cancer. 2005; 41:2438-48.

29. McCall P, Bennett L, Ahmad I, Mackenzie LM, Forbes IW, Leung HY, Sansom OJ, Orange C, Seywright M, Underwood MA, Edwards J. NFкB signaling is upregulated in a subset of castrate-resistant prostate cancer patients and correlates with disease progression. Br J Cancer. 2012; 107:1554-63.

30. Li L, Gao P, Li Y, Shen Y, Xie J, Sun D, Xue A, Zhao Z, Xu Z, Zhang M, Li B, Jiang J. JMJD2A-dependent silencing of $\mathrm{Sp} 1$ in advanced breast cancer promotes metastasis by downregulation of DIRAS3. Breast Cancer Res Treat. 2014; 147:487-500.

31. Yao JC, Wang L, Wei D, Gong W, Hassan M, Wu TT, Mansfield P, Ajani J, Xie K. Association between expression of transcription factor $\mathrm{Sp} 1$ and increased vascular endothelial growth factor expression, advanced stage, and poor survival in patients with resected gastric cancer. Clin Cancer Res. 2004; 10:4109-17.

32. Shi Q, Le X, Abbruzzese JL, Peng Z, Qian CN, Tang H, Xiong Q, Wang B, Li XC, Xie K. Constitutive Spl activity is essential for differential constitutive expression of vascular endothelial growth factor in human pancreatic adenocarcinoma. Cancer Res. 2001; 61:4143-54.

33. $\mathrm{Lu} \mathrm{S}$, Jenster G, Epner DE. Androgen induction of cyclin-dependent kinase inhibitor p21 gene: role of androgen receptor and transcription factor Sp1 complex. Mol Endocrinol. 2000; 14:753-60.

34. Hsu TI, Wang MC, Chen SY, Huang ST, Yeh YM, Su WC, Chang WC, Hung JJ. Betulinic acid decreases specificity protein ( $\mathrm{Sp} 1)$ level via increasing the sumoylation of Sp1 to inhibit lung cancer growth. Mol Pharmacol. 2012; 82:1115-28.

35. Gao Y, Jia Z, Kong X, Li Q, Chang DZ, Wei D, Le X, Suyun H, Huang S, Wang L, Xie K. Combining betulinic acid and mithramycin a effectively suppresses pancreatic cancer by inhibiting proliferation, invasion, and angiogenesis. Cancer Res. 2011; 71:5182-93. 
36. Chintharlapalli S, Papineni S, Ramaiah SK, Safe S. Betulinic acid inhibits prostate cancer growth through inhibition of specificity protein transcription factors. Cancer Res. 2007; 67:2816-23.

37. Hour TC, Chen J, Huang CY, Guan JY, Lu SH, Pu YS. Curcumin enhances cytotoxicity of chemotherapeutic agents in prostate cancer cells by inducing p21 (WAF1/CIP1) and $\mathrm{C} / \mathrm{EBP}$ beta expressions and suppressing NF-kappaB activation. Prostate. 2002; 51:211-8.

38. Mindnich RD, Penning TM. Aldo-keto reductase (AKR) superfamily: genomics and annotation. Human Genomics. 2009; 3:362-370.

39. Fung C, Dale W, Mohile SG. Prostate cancer in the elderly patient. J Clin Oncol. 2014; 32:2523-30.

40. Jia S, Gao X, Lee SH, Maira SM, Wu X, Stack EC, Signoretti S, Loda M, Zhao JJ, Roberts TM. Opposing effects of androgen deprivation and targeted therapy on prostate cancer prevention. Cancer Discovery. 2013; 3:44-51.

41. Shafi AA, Yen AE, Weigel NL. Androgen receptors in hormone-dependent and castration-resistant prostate cancer. Pharmacol Ther. 2013; 140:223-38.

42. Zhao Y, Tindall DJ, Huang H. Modulation of androgen receptor by FOXA1 and FOXO1 factors in prostate cancer. Int J Biol Sci. 2014; 10:614-9.

43. Dehm SM, Schmidt LJ, Heemers HV, Vessella RL, Tindall DJ. Splicing of a novel androgen receptor exon generates a constitutively active androgen receptor that mediates prostate cancer therapy resistance. Cancer Res. 2008; 68:5469-77.

44. Kim W, Zhang L, Wilton JH, Fetterly G, Mohler J, Weinberg V, Morse A, Szmulewitz RZ, Friedlander TW, Fong L, Lin AM, Harzstark AL, Molina A, et al. Sequential use of the androgen synthesis inhibitors ketoconazole and abiraterone acetate in castration-resistant prostate cancer and the predictive value of circulating androgens. Clin Cancer Res. 2014; 20:6269-76.

45. Fizazi K, Scher HI, Miller K, Basch E, Sternberg CN, Cella D, Forer D, Hirmand M, de Bono JS. Effect of enzalutamide on time to first skeletal-related event, pain, and quality of life in men with castration-resistant prostate cancer: results from the randomized, phase 3 AFFIRM trial. Lancet Oncol. 2014; 15:1147-56.

46. Arora VK, Schenkein E, Murali R, Subudhi SK, Wongvipat J, Balbas MD, Shah N, Cai L, Efstathiou E, Logothetis C, Zheng D, Sawyers CL. Glucocorticoid receptor confers resistance to antiandrogens by bypassing androgen receptor blockade. Cell. 2013; 155:1309-22.

47. Sweeney C, Liu G, Yiannoutsos C, Kolesar J, Horvath D, Staab MJ, Fife K, Armstrong V, Treston A, Sidor C, Wilding G. A phase II multicenter, randomized, double-blind, safety trial assessing the pharmacokinetics, pharmacodynamics, and efficacy of oral 2-methoxyestradiol capsules in hormone-refractory prostate cancer. Clin Cancer Res. 2005; 11:6625-33. 